\title{
A Micro-Scale Experimental Investigation on the Impact of Varying Stress on Geo- Mechanical Deformation of Proppant-Packed Fractured Shale
}

\author{
Mohammed Sayed ${ }^{*}$, Maziar Arshadi², Mohammad Piri² \\ 1. Aramco Services Company: Aramco Research Center - Houston, Houston, USA. \\ 2. University of Wyoming, Petroleum Engineering Department - Laramie, Wyoming, USA. \\ * Corresponding author: Mohammed.Sayed@Aramcoservices.com
}

The increasing demand for oil and gas resources has necessitated the exploitation of such resources from unconventional shale reservoirs [1]. In order to achieve economical production rates, hydraulic fracturing technology has been extensively used in the industry. Two main components are needed in hydraulic fracturing treatments; solid particles known as "proppant" to keep fractures open and allow for production of hydrocarbons, and a fluid, usually water and polymeric additives, to carry and place this proppant deep into the created fractures $[2,3]$. The proper placement of proppants within the created fractures provides the fracture its long term conductivity and therefore oil and gas productivity [4]. Proppant grains experience different types of deformation such as proppant diagenesis, breaking, crushing, fines migration, as well as embedment into the formation surface [5]. These deformation phenomena can result in a decline in production rates [6]. Proppant embedment and hence reduction in fracture conductivity has been investigated extensively [7,8]. Proppant concentration, type and size distribution as well as the mineralogy of the shale rock itself are critical factors in such phenomenon $[8,9]$.

We investigated the geo-mechanical deformation of proppant and rock surface related to using lightweight ceramic proppant (LWP) under increasing closure stress (up to $6500 \mathrm{psi}$ ) and its impact on the conductivity of induced fractures. The advantages of using LWP are the ability to increase the proppant load in the fracturing fluid, use less water, and place proppant better. A shale sample ( $8 \mathrm{~mm}$ in diameter and $50 \mathrm{~mm}$ in length) was fractured using the Brazilian test method [10] and packed with two to four layers of 30/50 mesh LWP. A state of the art carbon-fiber core-flow apparatus integrated with a highresolution X-ray micro-tomography system (Versa XRM-500) was used to perform the experiments. The X-ray source of which could reach a voltage of 30-160 kV and a power of 1-10 W achieving a resolution of $700 \mathrm{~nm}$ to $64 \mu \mathrm{m}$. The confining stress on the sample was increased in steps from to 500 to 6500 psi and then reduced once to $500 \mathrm{psi}$ to simulate fracturing/production/re-fracturing processes. The proppant pack was scanned at each stress increment to study the pore scale deformation of the proppant and fracture surface.

Fig. 1 presents a three-dimensional image of the entire core assembly and the proppant pack. LWP ceramic proppant is well-rounded and spherical in shape compared to white sand and resin coated sand [3]. Increasing the confining stress from 500 to 2500 psi did not result in any proppant embedment into the shale surface or any proppant crushing. This can be attributed to the fact that the well-rounded proppant was able to redistribute the higher confining stresses. When confining stress was increased to 6500 psi (Fig. 2), the proppant pack experienced some degree of embedment and some level of breaking where some of the proppant particles broke into two or three pieces. The propped fracture remained opened as a direct result of the re-distribution of the stresses among the proppant particles and hence the fracture conductivity needed was maintained.

Induced micro-fractures were observed in the shale matrix away from the main propped fracture (Fig. 3). Some proppant particles were able to move in to these induced fractures and keep them open under high 
stresses. When the stress was increased to $6500 \mathrm{psi}$, micro-fractures were created within the shale rock matrix (Fig. 4). Some of these micro-fractures closed as there was not enough proppant to support the stress. When the stress was reduced from 6500 to 500 psi, simulating a "re-fracturing process," these micro-fractures were reopened (Fig. 5). The main proppant-packed hydraulic fracture did not experience any significant change in aperture as it has maintained its opening over the increase in the confining stress.

The data show that X-ray micro-tomography/core-flow system is able to map the microscale deformation in the proppant pack/rock surface system. At this resolution, the proppant crushing, splitting, rearrangement and even embedment into the shale rock was detected. In addition, phenomenon such as induced micro-fractures, proppant migration and micro-fractures reopening were observed. Understanding geo-mechanical deformation of the proppant pack and fractured shale reservoirs could have significant impacts on the design of improved proppants, hydraulic fracturing treatments, and hence production scheme from such resources.

\section{References:}

[1] Energy Information administration (EIA), Annual Energy Outlook (2014)

[2] M Economides and T Martin (2007), Modern fracturing-enhancing natural gas production. BJ Service Company.

[3] Liang et al., Petroleum 2(1) (2016), p. 26.

[4] DG Gallagher, JPT 63(04) (2011), p. 18.

[5] C Xu et al., Journal of Natural Gas Science and Engineering 36 (2016), p. 1208.

[6] B Alramahi and MI Sundberg, ARMA-2012-291(2012).

[7] P Sanematsu et al., Journal of Petroleum Science and Engineering, 135 (2015), p. 391.

[8] M Arshadi et al., Advances in Water Resources 105 (2017), p. 108.

[9] J Parmar et al., Journal of Unconventional Oil and Gas Resources 5 (2014), p. 10.

[10] H Guo et al., Engineering Geology 33 (1993) p. 177.

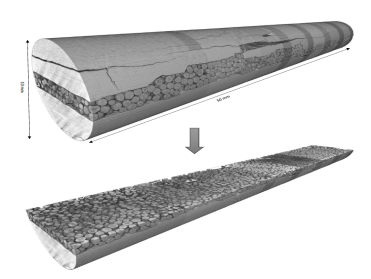

Figure 1. 3D image of the entire rock sample and the proppant pack.

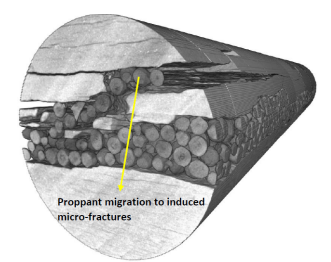

Figure 3. Proppant migration to micro-fractures.
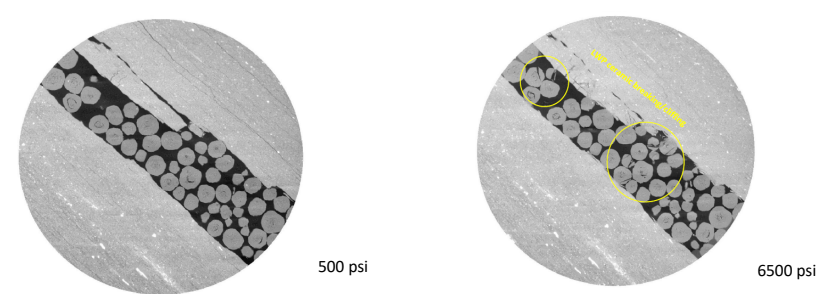

Figure 2. Geo-mechanical deformation of LWP ceramic under stress.

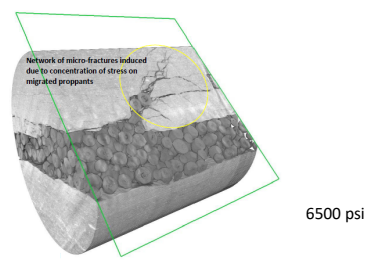

Figure 4. Secondary microfractures in the shale matrix.

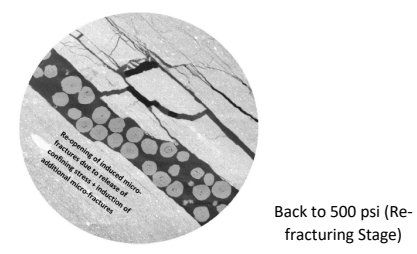

Figure 5. Micro-fractures reopening. 